AMPHETAMINES HAVE A HIGH POTENTIAL FOR ABUSE. ADMINISTRATION OF AMPHETAMINES FOR PROLONGED PERIODS OF TIME MAY LEAD TO DRUG DEPENDENCE AND MUST BE AVOIDED. PARTICULAR ATTENTION SHOULD BE PAID TO THE POSSIBILITY OF SUBJECTS OBTAINING AMPHETAMINES FOR NON-THERAPEUTIC USE OR DISTRIBUTION TO OTHERS, AND THE DRUGS SHOULD BE PRESCRIBED OR DISPENSED SPARINGLY.

MISUSE OF AMPHETAMINE MAY CAUSE SUDDEN DEATH AND SERIOUS CARDIOVASCULAR ADVERSE EVENTS.

\title{
DESCRIPTION:
}

A single entity amphetamine product combining the neutral sulfate salts of dextroamphetamine and amphetamine, with the dextro isomer of amphetamine saccharate and d, l-amphetamine aspartate monohydrate.

\begin{tabular}{|c|c|c|c|c|c|c|c|}
\hline & & & $\underline{10 \mathrm{~m}}$ & & & g & \\
\hline & 1. & $75 \mathrm{~m}$ & $2.5 \mathrm{n}$ & 25 & $.75 \mathrm{mg}$ & $5 \mathrm{~m}$ & $\overrightarrow{\mathrm{mg}}$ \\
\hline $\mathrm{Im}$ & el & & & & & $5 \mathrm{mg}$ & \\
\hline & & & & & & & \\
\hline & & & & & & $5 \mathrm{mg}$ & \\
\hline рілетантыс оa & $3.13 \mathrm{mg}$ &.$/ \mathrm{mg}$ & $6.3 \mathrm{mg}$ & $7.8 \mathrm{mg}$ & $9.4 \mathrm{mg}$ & $12.6 \mathrm{~m}$ & 8.81 \\
\hline
\end{tabular}

Inactive Ingredients: lactitol, microcrystalline cellulose, colloidal silicon dioxide, and magnesium stearate, and other ingredients.

Colors: ADDERALL ${ }^{\circledR} 5 \mathrm{mg}$ is a white to off-white tablet, which contains no color additives. ADDERALL $^{\circledR} 7.5 \mathrm{mg}$ and $10 \mathrm{mg}$ contain FD \& C Blue \#1.

ADDERALL $^{\circledR} 12.5 \mathrm{mg}, 15 \mathrm{mg}, 20 \mathrm{mg}$ and $30 \mathrm{mg}$ contain FD \& C Yellow \#6 as a color additive.

\section{CLINICAL PHARMACOLOGY:}

Amphetamines are non-catecholamine sympathomimetic amines with CNS stimulant activity. Peripheral actions include elevation of systolic and diastolic blood pressures and weak bronchodilator and respiratory stimulant action.

There is neither specific evidence which clearly establishes the mechanism whereby amphetamine produces mental and behavioral effects in children, nor conclusive evidence regarding how these effects relate to the condition of the central nervous system.

\section{Pharmacokinetics}

ADDERALL $^{\circledR}$ tablets contain d-amphetamine and 1-amphetamine salts in the ratio of $3: 1$. Following administration of a single dose 10 or $30 \mathrm{mg}$ of ADDERALL ${ }^{\circledR}$ to healthy volunteers under fasted conditions, peak plasma concentrations occurred approximately 3 hours post-dose for both damphetamine and l-amphetamine. The mean elimination half-life $\left(\mathrm{t}_{1 / 2}\right)$ for $\mathrm{d}$-amphetamine was shorter than the $\mathrm{t}_{1 / 2}$ of the 1-isomer (9.77-11 hours vs. 11.5-13.8 hours). The PK parameters $\left(\mathrm{C}_{\max }\right.$, $\mathrm{AUC}_{0 \text {-inf }}$ of d-and l-amphetamine increased approximately three-fold from $10 \mathrm{mg}$ to $30 \mathrm{mg}$ indicating dose-proportional pharmacokinetics. 
The effect of food on the bioavailability of ADDERALL ${ }^{\circledR}$ has not been studied.

\section{INDICATIONS:}

Attention Deficit Disorder with Hyperactivity: ADDERALL ${ }^{\circledR}$ is indicated as an integral part of a total treatment program which typically includes other remedial measures (psychological, educational, social) for a stabilizing effect in children with behavioral syndrome characterized by the following group of developmentally inappropriate symptoms: moderate to severe distractibility, short attention span, hyperactivity, emotional lability, and impulsivity. The diagnosis of this syndrome should not be made with finality when these symptoms are only of comparatively recent origin. Nonlocalizing (soft) neurological signs, learning disability and abnormal EEG may or may not be present, and a diagnosis of central nervous system dysfunction may or may not be warranted.

\section{In Narcolepsy}

\section{CONTRAINDICATIONS:}

Advanced arteriosclerosis, symptomatic cardiovascular disease, moderate to severe hypertension, hyperthyroidism, known hypersensitivity or idiosyncrasy to the sympathomimetic amines, glaucoma.

Agitated states.

Patients with a history of drug abuse.

During or within 14 days following the administration of monoamine oxidase inhibitors (hypertensive crises may result).

\section{WARNINGS:}

Psychosis: Clinical experience suggests that in psychotic children, administration of amphetamine may exacerbate symptoms of behavior disturbance and thought disorder.

Long-Term Suppression of Growth: Data are inadequate to determine whether chronic administration of amphetamine may be associated with growth inhibition; therefore, growth should be monitored during treatment.

Sudden Death and Pre-existing Structural Cardiac Abnormalities: Sudden death has been reported in association with amphetamine treatment at usual doses in children with structural cardiac abnormalities. Adderall generally should not be used in children or adults with structural cardiac abnormalities.

Usage in Nursing Mothers: Amphetamines are excreted in human milk. Mothers taking amphetamines should be advised to refrain from nursing.

\section{PRECAUTIONS:}

General: The least amount feasible should be prescribed or dispensed at one time in order to minimize the possibility of overdosage.

Hypertension: Caution is to be exercised in prescribing amphetamines for patients with even mild hypertension. Blood pressure and pulse should be monitored at appropriate intervals in patients taking Adderall, especially patients with hypertension. 
Information for Patients: Amphetamines may impair the ability of the patient to engage in potentially hazardous activities such as operating machinery or vehicles; the patient should therefore be cautioned accordingly.

Drug Interactions: Acidifying agents -Gastrointestinal acidifying agents (guanethidine, reserpine, glutamic acid $\mathrm{HCl}$, ascorbic acid, fruit juices, etc.) lower absorption of amphetamines.

Urinary acidifying agents -(ammonium chloride, sodium acid phosphate, etc.) Increase the concentration of the ionized species of the amphetamine molecule, thereby increasing urinary excretion. Both groups of agents lower blood levels and efficacy of amphetamines.

Adrenergic blocker-Adrenergic blockers are inhibited by amphetamines.

Alkalinizing agents -Gastrointestinal alkalinizing agents (sodium bicarbonate, etc.) increase absorption of amphetamines. Urinary alkalinizing agents (acetazolamide, some thiazides) increase the concentration of the non-ionized species of the amphetamine molecule, thereby decreasing urinary excretion. Both groups of agents increase blood levels and therefore potentiate the actions of amphetamines.

Antidepressants, tricyclic-Amphetamines may enhance the activity of tricyclic or sympathomimetic agents; d-amphetamine with desipramine or protriptyline and possibly other tricyclics cause striking and sustained increases in the concentration of d-amphetamine in the brain; cardiovascular effects can be potentiated.

MAO inhibitors -MAOI antidepressants, as well as a metabolite of furazolidone, slow amphetamine metabolism. This slowing potentiates amphetamines, increasing their effect on the release of norepinephrine and other monoamines from adrenergic nerve endings; this can cause headaches and other signs of hypertensive crisis. A variety of neurological toxic effects and malignant hyperpyrexia can occur, sometimes with fatal results.

Antihistamines -Amphetamines may counteract the sedative effect of antihistamines.

Antihypertensives -Amphetamines may antagonize the hypotensive effects of antihypertensives.

Chlorpromazine-Chlorpromazine blocks dopamine and norepinephrine receptors, thus inhibiting the central stimulant effects of amphetamines, and can be used to treat amphetamine poisoning.

Ethosuximide -Amphetamines may delay intestinal absorption of ethosuximide.

Haloperidol -Haloperidol blocks dopamine receptors, thus inhibiting the central stimulant effects of amphetamines.

Lithium carbonate -The anorectic and stimulatory effects of amphetamines may be inhibited by lithium carbonate.

Meperidine-Amphetamines potentiate the analgesic effect of meperidine.

Methenamine therapy -Urinary excretion of amphetamines is increased, and efficacy is reduced, by acidifying agents used in methenamine therapy.

Norepinephrine-Amphetamines enhance the adrenergic effect of norepinephrine.

Phenobarbital -Amphetamines may delay intestinal absorption of phenobarbital; co-administration of phenobarbital may produce a synergistic anticonvulsant action.

Phenytoin -Amphetamines may delay intestinal absorption of phenytoin; co-administration of phenytoin may produce a synergistic anticonvulsant action.

Propoxyphene -In cases of propoxyphene overdosage, amphetamine CNS stimulation is potentiated and fatal convulsions can occur.

Veratrum alkaloids -Amphetamines inhibit the hypotensive effect of veratrum alkaloids.

\section{Drug/Laboratory Test Interactions:}

- Amphetamines can cause a significant elevation in plasma corticosteroid levels. This increase is greatest in the evening.

- Amphetamines may interfere with urinary steroid determinations. 
Carcinogenesis/Mutagenesis: Mutagenicity studies and long-term studies in animals to determine the carcinogenic potential of amphetamine, have not been performed.

Pregnancy - Teratogenic Effects: Pregnancy Category C. Amphetamine has been shown to have embryotoxic and teratogenic effects when administered to A/Jax mice and C57BL mice in doses approximately 41 times the maximum human dose. Embryotoxic effects were not seen in New Zealand white rabbits given the drug in doses 7 times the human dose nor in rats given 12.5 times the maximum human dose. While there are no adequate and well-controlled studies in pregnant women, there has been one report of severe congenital bony deformity, tracheoesophageal fistula, and anal atresia (vater association) in a baby born to a woman who took dextroamphetamine sulfate with lovastatin during the first trimester of pregnancy. Amphetamines should be used during pregnancy only if the potential benefit justifies the potential risk to the fetus.

Nonteratogenic Effects: Infants born to mothers dependent on amphetamines have an increased risk of premature delivery and low birth weight. Also, these infants may experience symptoms of withdrawal as demonstrated by dysphoria, including agitation, and significant lassitude.

Pediatric Use: Long-term effects of amphetamines in children have not been well established. Amphetamines are not recommended for use in children under 3 years of age with Attention Deficit Disorder with Hyperactivity described under INDICATIONS AND USAGE.

Amphetamines have been reported to exacerbate motor and phonic tics and Tourette's syndrome.

Therefore, clinical evaluation for tics and Tourette's syndrome in children and their families should precede use of stimulant medications.

Drug treatment is not indicated in all cases of Attention Deficit Disorder with Hyperactivity and should be considered only in light of the complete history and evaluation of the child. The decision to prescribe amphetamines should depend on the physician's assessment of the chronicity and severity of the child's symptoms and their appropriateness for his/her age. Prescription should not depend solely on the presence of one or more of the behavioral characteristics. When these symptoms are associated with acute stress reactions, treatment with amphetamines is usually not indicated.

\section{ADVERSE REACTIONS:}

Cardiovascular: Palpitations, tachycardia, elevation of blood pressure, sudden death, myocardial infarction. There have been isolated reports of cardiomyopathy associated with chronic amphetamine use.

Central Nervous System: Psychotic episodes at recommended doses (rare), overstimulation, restlessness, dizziness, insomnia, euphoria, dyskinesia, dysphoria, depression, tremor, headache, exacerbation of motor and phonic tics and Tourette's syndrome, seizures, stroke.

Gastrointestinal: Dryness of the mouth, unpleasant taste, diarrhea, constipation, other gastrointestinal disturbances. Anorexia and weight loss may occur as undesirable effects when amphetamines are used for other than the anorectic effect.

Allergic: Urticaria.

Endocrine: Impotence, changes in libido.

DRUG ABUSE AND DEPENDENCE: 
Dextroamphetamine Sulfate, Amphetamine Sulfate, Amphetamine Aspartate Monohydrate, and Dextroamphetamine Saccharate are Schedule II controlled substance. Amphetamines have been extensively abused. Tolerance, extreme psychological dependence, and severe social disability have occurred. There are reports of patients who have increased the dosage to many times than recommended. Abrupt cessation following prolonged high dosage administration results in extreme fatigue and mental depression; changes are also noted on the sleep EEG. Manifestations of chronic intoxication with amphetamines include severe dermatoses, marked insomnia, irritability, hyperactivity, and personality changes. The most severe manifestation of chronic intoxication is psychosis, often clinically indistinguishable from schizophrenia. This is rare with oral amphetamines.

\section{OVERDOSAGE:}

Individual patient response to amphetamines varies widely. While toxic symptoms occasionally occur as an idiosyncrasy at doses as low as $2 \mathrm{mg}$, they are rare with doses of less than $15 \mathrm{mg}$; $30 \mathrm{mg}$ can produce severe reactions, yet doses of 400 to $500 \mathrm{mg}$ are not necessarily fatal.

In rats, the oral $\mathrm{LD}_{50}$ of dextroamphetamine sulfate is $96.8 \mathrm{mg} / \mathrm{kg}$.

Symptoms: Manifestations of acute overdosage with amphetamines include restlessness, tremor, hyperreflexia, rapid respiration, confusion, assaultiveness, hallucinations, panic states, hyperpyrexia and rhabdomyolysis.

Fatigue and depression usually follow the central stimulation.

Cardiovascular effects include arrhythmias, hypertension or hypotension and circulatory collapse.

Gastrointestinal symptoms include nausea, vomiting, diarrhea, and abdominal cramps. Fatal poisoning is usually preceded by convulsions and coma.

Treatment: Consult with a Certified Poison Control Center for up to date guidance and advice. Management of acute amphetamine intoxication is largely symptomatic and includes gastric lavage, administration of activated charcoal, administration of a cathartic and sedation. Experience with hemodialysis or peritoneal dialysis is inadequate to permit recommendation in this regard. Acidification of the urine increases amphetamine excretion, but is believed to increase risk of acute renal failure if myoglobinuria is present. If acute, severe hypertension complicates amphetamine overdosage, administration of intravenous phentolamine has been suggested. However, a gradual drop in blood pressure will usually result when sufficient sedation has been achieved. Chlorpromazine antagonizes the central stimulant effects of amphetamines and can be used to treat amphetamine intoxication.

\section{DOSAGE AND ADMINISTRATION:}

Regardless of indication, amphetamines should be administered at the lowest effective dosage and dosage should be individually adjusted. Late evening doses should be avoided because of the resulting insomnia.

Attention Deficit Disorder with Hyperactivity: Not recommended for children under 3 years of age. In children from 3 to 5 years of age, start with $2.5 \mathrm{mg}$ daily; daily dosage may be raised in increments of $2.5 \mathrm{mg}$ at weekly intervals until optimal response is obtained.

In children 6 years of age and older, start with $5 \mathrm{mg}$ once or twice daily; daily dosage may be raised in increments of $5 \mathrm{mg}$ at weekly intervals until optimal response is obtained. Only in rare cases will it 
be necessary to exceed a total of $40 \mathrm{mg}$ per day. Give first dose on awakening; additional doses ( 1 or 2) at intervals of 4 to 6 hours.

Where possible, drug administration should be interrupted occasionally to determine if there is a recurrence of behavioral symptoms sufficient to require continued therapy.

Narcolepsy: Usual dose $5 \mathrm{mg}$ to $60 \mathrm{mg}$ per day in divided doses, depending on the individual patient response.

Narcolepsy seldom occurs in children under 12 years of age; however, when it does, dextroamphetamine sulfate may be used. The suggested initial dose for patients aged 6-12 is $5 \mathrm{mg}$ daily; daily dose may be raised in increments of $5 \mathrm{mg}$ at weekly intervals until optimal response is obtained. In patients 12 years of age and older, start with $10 \mathrm{mg}$ daily; daily dosage may be raised in increments of $10 \mathrm{mg}$ at weekly intervals until optimal response is obtained. If bothersome adverse reactions appear (e.g., insomnia or anorexia), dosage should be reduced. Give first dose on awakening; additional doses ( 1 or 2 ) at intervals of 4 to 6 hours.

\section{HOW SUPPLIED:}

ADDERALL ${ }^{\circledR} 5 \mathrm{mg}$ : A round, flat-faced beveled edge, white to off-white tablet, " 5 " embossed on one side with partial bisect and "AD" embossed on the other side (NDC 54092-371-01)

ADDERALL ${ }^{\circledR} 7.5 \mathrm{mg}$ : An oval, convex, blue tablet, "7.5" embossed on one side with a partial bisect and "AD" embossed on the other side with a full and partial bisect (NDC 54092-372-01)

ADDERALL ${ }^{\circledR} 10 \mathrm{mg}$ : A round, convex, blue tablet, "10" embossed on one side with a full and partial bisect and "AD" embossed on the other side (NDC 54092-373-01)

ADDERALL ${ }^{\circledR} 12.5 \mathrm{mg}$ : A round, flat-faced beveled edge, orange tablet, "12.5" embossed on one side and "AD" embossed on the other side with a full and partial bisect (NDC 54092-374-01)

ADDERALL ${ }^{\circledR} 15 \mathrm{mg}$ : An oval, convex, orange tablet, "15" embossed on one side with a partial bisect and "AD" embossed on the other side with a full and partial bisect (NDC 54092-375-01)

ADDERALL ${ }^{\circledR} 20 \mathrm{mg}$ : A round, convex, orange tablet, "20" embossed on one side with a full and partial bisect and "AD" embossed on the other side (NDC 54092-376-01)

ADDERALL ${ }^{\circledR} 30 \mathrm{mg}$ : A round, flat-faced beveled edge, orange tablet, "30" embossed on one side with a full and partial bisect and "AD" embossed on the other side (NDC 54092-377-01)

In bottles of 100 tablets.

Dispense in a tight, light-resistant container as defined in the USP.

Store at $25^{\circ} \mathrm{C}\left(77^{\circ} \mathrm{F}\right)$, excursions permitted to $15^{\circ}-30^{\circ} \mathrm{C}\left(59-86^{\circ} \mathrm{F}\right)$ [see USP Controlled Room Temperature]

\section{Rx only.}


Manufactured for: $\quad$ Shire US Inc.

725 Chesterbrook Blvd.

Wayne, PA 19087

Manufactured by: $\quad$ DSM Pharmaceuticals Inc. 5900 NW Greenville Blvd.

Made in USA Greenville, NC 27834

1-800-828-2088

(C)2005 Shire US Inc. 